\title{
Our ACE in the HOLE: Justifying the Use of Angiotensin-converting Enzyme Inhibitors as Adjuvants to Standard Chemotherapy
}

\author{
DANIEL P. RADIN ${ }^{1}$, AUSTIN KREBS $^{2}$, ARMAN MAQSUDLU $^{2}$ and PARTH PATEL ${ }^{3}$ \\ ${ }^{1}$ Department of Pharmacology, Stony Brook University School of Medicine, Stony Brook, NY, U.S.A.; \\ ${ }^{2}$ Department of Pharmacology and Experimental Therapeutics, Boston University, Boston, MA, U.S.A.; \\ ${ }^{3}$ College of Arts and Sciences, New York University, New York, NY, U.S.A.
}

\begin{abstract}
Angiotensin-I-converting enzyme (ACE) inhibitors have been very effective in treating cardiac hypertension since their clinical inception over four decades ago. Since then, it has been established that angiotensin II, the product of ACE, has oncogenic and pro-proliferative qualities, which begs the question as to whether ACE inhibitors may have oncolytic characteristics. In fact, scattered reports suggest that ACE inhibitors are oncolytic and oncopreventive, but the available literature has yet to be thoroughly examined. In the present review, we examine the available literature and determine that $A C E$ inhibitors would have great utility in the prevention and treatment of cancer. At the same time, they would augment the efficacy of chemo- and radiotherapy as well as mitigating damage to healthy tissue by standard chemotherapeutic regimens. We review some of the mounting clinical evidence and show that ACE inhibitors have oncolytic activity in multiple types of cancer and discuss the ability of ACE inhibitors to prevent cardiotoxicity of multiple chemotherapies. Our analysis demonstrates that the actions of ACE inhibitors converge on vascular endolthelial growth factor to reduce its levels in tumors and prevent construction of blood vessels to masses, leaving them nutrient-depleted and subsequently hindering their growth. Given that ACE inhibitors are approved by the Federal Drug Administration and the therapeutic dose for hypertension treatment also slows the growth of multiple cancers types, $A C E$ inhibitors are in a perfect position to be repurposed as oncolytic agents, that would widely increase their utility in the clinic.
\end{abstract}

Correspondence to: Daniel P. Radin, Department of Pharmacology, Stony Brook University School of Medicine, Stony Brook, 11790 NY, U.S.A. Tel: +1 2016790671, e-mail: danradin1@gmail.com

Key Words: Angiontensin-I-converting enzyme, angiotensin-II, captopril, metastatic cancer, VEGF, review.
Angiotensin-I-converting enzyme (ACE) inhibitors have faithfully treated hypertension and congestive heart failure since their introduction into the clinic over 40 years ago (1). Since the inception of the first ACE inhibitor, captopril, several others have reached the clinic. They are usually prescribed along with other hypertensive drugs to address individual patient treatment requirements. Mechanistically, ACE inhibitors block the conversion of angiotensin I to angiotensin II and subsequent downstream physiological consequences such as arteriolar vasoconstriction and increased blood pressure. Interestingly, angiotensin II has pro-proliferative capabilities in smooth muscle cells (2) and has been shown to facilitate breast cancer cell migration and metastasis (3), suggesting that ACE inhibition may have oncolytic effects.

In a nested case-control study, researchers found that men taking captopril for hypertension were at a reduced risk for developing prostate cancer compared to matched controls (1). Furthermore, Kubota et al. (4) reported that captopril reduces azoxymethane-induced colonic preneoplastic lesions in obese mice, thus demonstrating that captopril has cancerpreventing effects. Similar results were corroborated by Fendrich et al. (5) who reported that enalapril, another ACE inhibitor, delays pancreatic cancer formation in genetically engineered mice. There are also data that demonstrate that ACE inhibitors slow tumor growth (7) and prevent toxicity to healthy tissue (6).

This mounting evidence demonstrates that ACE inhibitors may have utility in the clinic beyond the treatment of hypertension. Therefore, we set out to review the existing evidence that ACE inhibitors have oncopreventive effects, and may exhibit direct oncolytic activity in certain cancer types. We attempt to determine the cancer types for which ACE inhibitors may elicit the greatest therapeutic benefit and make an argument for why ACE inhibitors should be 
administered alongside DNA-damaging agents to prevent toxicity to healthy tissue in pediatric cancer patients.

\section{Oncopreventive Nature of ACE Inhibitors}

Currently, ACE inhibitors are Federal Drug Administation (FDA) approved to prevent the conversion of angiotensin I to angiotensin II. Growing implicates angiotensin II as exhibiting oncogenic and pro-proliferative effects $(2,3)$. As a result, it is likely that adults taking ACE inhibitors to manage cardiac hypertension may be at reduced risk for the development of certain kinds of cancer. In support of this notion, Ronquist et al. (1) determined that captopril, an ACE inhibitor that penetrates the blood-seminal plasma barrier, reduces the incidence of prostate cancer in adult males. This reduction in incidence was found to be dose- and durationdependent. In particular, patients taking captopril for ischemic heart disease were at $70 \%$ reduced risk for the development of prostate cancer, a statistically significant finding (1).

More elegant mechanistic studies performed in mice with genetically or pharmacologically induced cancer shed additional light on the molecular consequences of ACE inhibitors in cancer models. In obese mice administered azoxymethane (a mutagen and cancer-promoting agent), captopril reduced the number of malignant preneoplastic lesions and the amount of DNA damage in the colon, demonstrating that it may nullify some of the oncogenic effects of azoxymethane (4). Interestingly, it was reported that captopril seemed to exert this oncopreventive role not only by reducing oxidative stress but also by serving as antiinflammatory agent (4). In particular, it was observed that captopril treatment lowered the levels of 8-hydroxydeoxyguanosine, which is a marker of DNA damage induced by oxidative stress, as well as DNA damage itself brought on by azoxymethane pretreatment (4). Moreover, among obese mice pre-treated with azoxymethane captopril lowered the mRNA expression of the following pro-inflammatory cytokines: interleukin-1-beta and interleukin-6. As a consequence, captopril may reduce the incidence of colorectal cancer by lowering systemic inflammation (4).

In mice genetically engineered to develop pancreatic cancer, enalopril down-regulated vascular endothelial growth factor $(V E G F)$ mRNA and nuclear factor kappa beta (NFKB) (5). VEGF is required to build blood vessels that transport nutrients to tumors in order to meet their high energy demands and NFKB is a transcription factor that promotes the production of oncogenic proteins (5). Thus, the downregulation of these two proteins by an ACE inhibitor may explain why chronic use for hypertension may reduce the risk of certain types of cancer. If tumors in patients being treated for hypertension or congestive heart failure cannot form blood vessels, such tumors will never propagate and grow enough to threaten the life of the patient.

\section{ACE Inhibitors as Radio/Chemosensitizers and Oncolytic Agents}

Since data have demonstrated that ACE inhibitors are in fact oncopreventive, it is necessary to examine whether these drugs can halt the growth and spread of existing tumors. In vitro, ACE inhibitors do not seem to demonstrate considerable oncolytic activity. However, in pre-clinical mouse models, ACE inhibitors have been shown to exert a significant oncolytic effect in multiple cancer types. In particular, in liver tumors, ACE inhibitors perindopril and candesartan dose-dependently were found to reduce angiogenesis and tumor growth by reducing the quantity of VEGF and subsequently lower tumor microvascular density $(8,10)$. Similar effects were likewise observed on VEGF and microvascular density when perindopril and captopril were used to treat head and neck cancer and renal cancer, respectively $(7,9)$. Moreover, captopril reduced metastasis of tumors to the lungs (9). This result is particularly encouraging due to the association of metastasis with higher grade cancer that often have dismal prognosis.

The efficacy of ACE inhibitors in reducing angiogenesis and tumor growth has been largely attributed to the overexpression of angiotensin II type I receptor (AGTR1). In fact, it has been widely studied that the overexpression of AGTR1 has been found in liver, breast, renal, pancreatic, bladder, prostate, ovarian, cervical, laryngeal, head and neck, and skin squamous cell cancer $(10,11)$. In cancer, angiotensin II up-regulates $A G T R 1$, which in turn activates the extracellular signal-related kinase/protein kinase B pathways, resulting in increased VEGF production (12) (Figure 1). As a result, inhibition of AGTR1 through ACE inhibitors have been theorized to reduce not only VEGF but also angiogenesis and tumor growth $(10,12)$. In particular, in liver xenografts, oral administration of candesartan at either 2 or $10 \mathrm{mg} / \mathrm{kg} /$ day lowered the expression of VEGF and restricted the formation of neo-vessels (10). As a consequence, it is believed that ACE inhibitors, like candesartan restrict tumor growth and exhibit oncolytic effects in vivo by inhibiting the formation of new blood vessels to solid tumors (10).

An elegant study performed by Namazi et al. (13), demonstrated that MCF-7 estrogen-receptor positive breast cancer cells acquire resistance to tamoxifen, an estrogen receptor antagonist, after chronic treatment with this agent. Concomitant treatment of cancer cells with tamoxifen and captopril negated this acquired resistance and maintained sensitivity of these cells to tamoxifen over a longer period of time. This pre-clinical result is particularly encouraging because acquired resistance to chemotherapies is a major obstacle in the clinical treatment of cancer. In some cases, chemotherapy appears to slow cancer growth, but the cells that make up the tumor acquire a resistance to the treatment. 


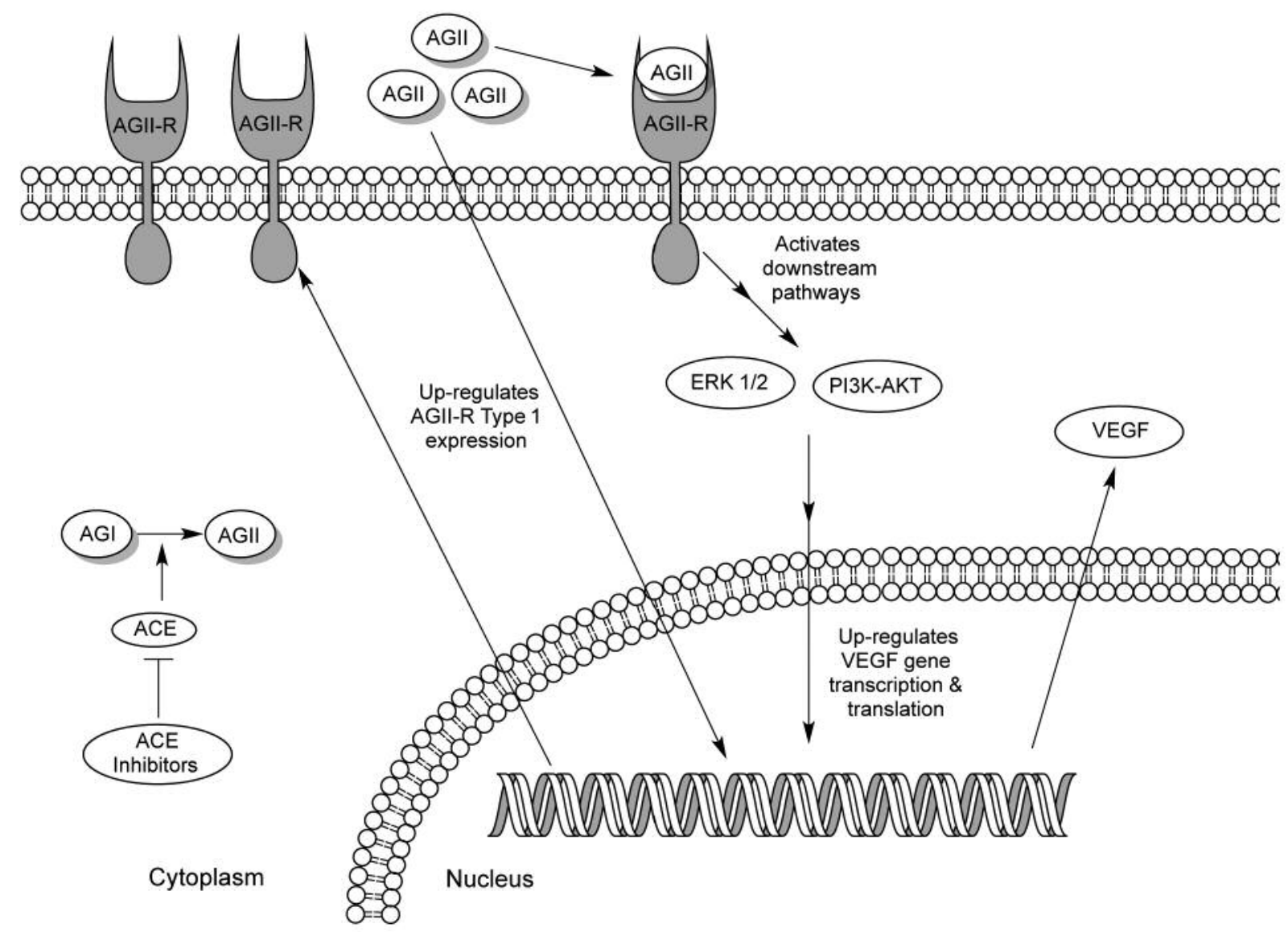

Figure 1. Schematic pathway diagram of the oncogenic actions of angiontensinconverting enzyme (ACE) in cancer and inhibition by ACE inhibitors approved by the federal drug administration. Angiotensin I (AGI) conversion to angiotensin II (AGII) and binding to its conjugate receptor (AGII-R) initiates an extracellular signal-related-1/2 (ERK1/2) and phosphatidylinositol 3-kinase/protein kinase B (PI3K/AKT) signaling cascade which results in up regulation of vascular endothelial growth factor-alpha (VEGFA). Inhibition of angiotensin II production results in decreased VEGF production and mitigated microvascular production, which corresponds to lowered nutrient uptake and stunted tumor growth in vivo.

As a result, a second, potentially more toxic second-line treatment must be used to treat the patient. If ACE inhibitors can prevent acquired resistance to front-line chemotherapies, patient outcomes may improve considerably. Similarly, captopril has been shown to enhance cisplatin efficacy in vivo and independently reduce the size of gastric cancers by up to $50 \%$ (14). In addition, enalapril was found to enhance radioimmunotherapy in human colon cancer xenografts (15).

There is also mounting clinical evidence that ACE inhibitors may have a positive impact on patient outcomes by slowing the progression of several cancer types. Liu et al. (16) recently demonstrated that lisinopril extends the median survival time of patients with non-metastatic pancreatic ductal adenocarcinoma from 19.3 to 36.3 months. The activity of several oncogenic pathways was reduced in the tumor, and the activity of effector T-cells and antigenpresenting cells increased drastically, demonstrating that
ACE inhibitors may be able to elicit an antitumor immune response in patients. On a cellular level, this significant clinical finding may be explained by previous studies demonstrating that poorly differentiated pancreatic tumors are particularly susceptible to VEGF inhibition (17). By inhibiting the production of VEGF rather than its binding to its conjugate receptor, one would expect a similar functional outcome, underpinned by increased median survival time of patients. In patients with lung and kidney cancer, adding an ACE inhibitor $(18,19)$ extended the median survival time of patients, and in some cases produced a complete remission of the tumor (19). Patients that received sunitinib with a supplemental ACE inhibitor experienced an increase in progression-free survival time of from 6 to 13 months, a statistically significant finding (20). These data, in addition with data from elegant pre-clinical studies, suggest that ACE inhibitors may have a wide utility in cancer prevention and 
treatment and may bolster the effects of existing front-line treatments for multiple cancers.

\section{ACE Inhibitors as Cardioprotective Agents}

A common difficulty with chemotherapy is the damage done to non-malignant tissue by DNA-damaging agents, which requires the cessation of the chemotherapy regimen. This is especially true in pediatric patients, as their hearts are very sensitive to toxicity elicited by standard chemotherapies (6). To date, two independent reports have demonstrated that enalapril, at doses used to manage hypertension prevents cardiac decline in survivors of pediatric cancer (6). Furthermore, enalapril has been shown to prevent cardiotoxicity from high-dose chemotherapy in high-risk patients. In particular, enalapril successfully prevented cardiac decline in pediatric cancer patients after 12 months, whereas those receiving high-dose chemotherapy plus placebo experienced a time-dependent decline in cardiac output.

\section{Future Directions}

The current work demonstrates that ACE inhibitors can act as oncopreventive agents as well as oncolytic agents. ACE inhibitors can also increase the efficacy of standard radioand chemotherapy, and prevent toxicity to other, healthy organs. Furthermore, there is definitive clinical evidence that ACE inhibitors improve clinical outcomes for patients with different types of cancer when combined with standard chemotherapeutic regimens.

Research should continue to explore the potential therapeutic benefits of ACE inhibitors in the contexts discussed here. As a class of FDA-approved drugs, repurposing ACE inhibitors into oncolytic agents and preventative measures for cancer and chemotherapyassociated side-effects has the potential to be both cost- and time-effective. It seems that ACE inhibitors would be of particular use in managing VEGF-driven cancer, as most of the published oncolytic effects of ACE inhibitors appear to be VEGF-dependent. Furthermore, given that captopril prevents glioma cell invasion (22), future research should explore the potential for ACE inhibitors that penetrate the blood-brain barrier to treat cancer which arises from the central nervous system. This is especially important given the dismal prognoses of most patients with brain cancer and the inability of many drugs developed to treat this disease to pass through the blood-brain barrier due to size or charge constraints. With these ideas in mind, supplementing standard chemotherapeutic regimens with ACE inhibitors would be a simple and efficient way of determining which cancer types might be managed more effectively with the addition of a widely-distributed drug that has already been approved by the FDA.

\section{References}

1 Ronquist G, Rodriguez LA, Ruigomez A, Johansson S, Wallander MA, Frithz G and Svardsudd K: Association between captopril, other antihypertensive drugs and risk of prostate cancer. Prostate 58(1): 50-56, 2004.

2 Daemen MJ, Lombardi DM, Bosman FT and Schwartz SM: Angiotensin II induces smooth muscle cell proliferation in the normal and injured rat arterial wall. Circ Res 68(2): 450-456, 1991.

3 Rodrigues-Ferreira S, Abdelkarim M, Dillenburg-Pilla P, Luissint AC, di-Tommaso A, Deshayes F, Pontes CL, Molina A, Cagnard N, Letourneur F, Morel M, Reis RI, Casarini DE, Terris B, Couraud PO, Costa-Neto CM, Di Benedetto M and Nahmias C: Angiotensin II facilitates breast cancer cell migration and metastasis. PLoS One 7(4): e35667, 2012.

4 Kubota M, Shimizu M, Sakai H, Yasuda Y, Ohno T, Kochi T, Tsurumi $\mathrm{H}$, Tanaka $\mathrm{T}$ and Moriwaki $\mathrm{H}$ : Renin-angiotensin system inhibitors suppress azoxymethane induced colonic preneoplastic lesions in $\mathrm{c} 57 \mathrm{bl} / \mathrm{ksj}-\mathrm{db} / \mathrm{db}$ obese mice. Biochem Biophys Res Commun 410(1): 108-113, 2011.

5 Fendrich V, Chen NM, Neef M, Waldmann J, Buchholz M, Feldmann G, Slater EP, Maitra A and Bartsch DK: The angiotensin-I-converting enzyme inhibitor Enalapril and aspirin delay progression of pancreatic intraepithelial neoplasia and cancer formation in a genetically engineered mouse model of pancreatic cancer. Gut 59(5): 630-637, 2010.

6 Silber JH, Cnaan A, Clark BJ, Paridon SM, Chin AJ, Rychik J, Hogarty AN, Cohen MI, Barber G, Rutkowski M, Kimball TR, Delaat C, Steinherz LJ and Zhao H: Enalapril to prevent cardiac function decline in long-term survivors of pediatric cancer exposed to anthracyclines. J Clin Oncol 22(5): 820-828, 2004.

7 Yasumatsu R, Nakashima T, Masuda M, Ito A, Kuratomi Y, Nakagawa $\mathrm{T}$ and Komune $\mathrm{S}$ : Effects of the angiotensin-Iconverting enzyme inhibitor perindopril on tumor growth and angiogenesis in head and neck squamous cell carcinoma cells. J Cancer Res Clin Oncol 130(10): 567-573, 2004.

8 Yoshiji H, Kuriyama S, Kawata M, Yoshii J, Ikenaka Y, Noguchi $\mathrm{R}$, Nakatani $\mathrm{T}$, Tsujinoue $\mathrm{H}$ and Fukui $\mathrm{H}$ : The angiotensin-Iconverting enzyme inhibitor perindopril suppresses tumor growth and angiogenesis: Possible role of the vascular endothelial growth factor. Clin Cancer Res 7(4): 1073-1078, 2001.

9 Araujo WF, Naves MA, Ravanini JN, Schor N and Teixeira VP: Renin-angiotensin system (RAS) blockade attenuates growth and metastatic potential of renal cell carcinoma in mice. Urol Oncol 33(9): 389 e381-387, 2015.

10 Fan F, Tian C, Tao L, Wu H, Liu Z, Shen C, Jiang G and Lu Y: Candesartan attenuates angiogenesis in hepatocellular carcinoma via down-regulating AT1R/VEGF pathway. Biomed Pharmacother 83: 704-711, 2016.

11 Oh E, Kim JY, Cho Y, An H, Lee N, Jo H, Ban C and Seo JH: Overexpression of angiotensin ii type 1 receptor in breast cancer cells induces epithelial mesenchymal transition and promotes tumor growth and angiogenesis. Biochim Biophys Acta $1863(6$ Pt A): 1071-1081, 2016.

12 Liu C, Zhang JW, Hu L, Song YC, Zhou L, Fan Y, Zhu HY, Wang Y and Li QP: Activation of the AT1R/HIF-1 alpha/ACE axis mediates angiotensin ii-induced Vegf synthesis in mesenchymal stem cells. Biomed Res Int 2014: 627380, 2014. 
13 Namazi S, Rostami-Yalmeh J, Sahebi E, Jaberipour M, Razmkhah M and Hosseini A: The role of captopril and losartan in prevention and regression of tamoxifen induced resistance of breast cancer cell line MCF-7: An in vitro study. Biomed Pharmacother 68(5): 565-571, 2014.

14 Williams RN, Parsons SL, Morris TM, Rowlands BJ and Watson SA: Inhibition of matrix metalloproteinase activity and growth of gastric adenocarcinoma cells by an angiotensin converting enzyme inhibitor in in vitro and murine models. Eur J Surg Oncol 31(9): 1042-1050, 2005.

15 Kinuya S, Yokoyama K, Kawashima A, Hiramatsu T, Konishi S, Shuke N, Watanabe N, Takayama T, Michigishi T and Tonami $\mathrm{N}$ : Pharmacologic intervention with angiotensin II and kininase inhibitor enhanced efficacy of radioimmunotherapy in human colon cancer xenografts. J Nucl Med 41(7): 1244-1249, 2000.

16 Liu H, Naxerova K, Pinter M, Incio J, Lee H, Shigeta K, Ho WW, Crain JA, Jacobson A, Michelakos T, Dias-Santos D, Zanconato A, Hong TS, Clark JW, Murphy JE, Ryan DP, Deshpande V, Lillemoe KD, Fernandez-Del Castillo C, Downes M, Evans RM, Michaelson J, Ferrone CR, Boucher Y and Jain RK: Use of angiotensin system inhibitors is associated with immune activation and longer survival in nonmetastatic pancreatic ductal adenocarcinoma. Clin Cancer Res 23(19): 5959-5969, 2017.

17 Rhim AD, Oberstein PE, Thomas DH, Mirek ET, Palermo CF, Sastra SA, Dekleva EN, Saunders T, Becerra CP, Tattersall IW, Westphalen CB, Kitajewski J, Fernandez-Barrena MG, FernandezZapico ME, Iacobuzio-Donahue C, Olive KP and Stanger BZ: Stromal elements act to restrain, rather than support, pancreatic ductal adenocarcinoma. Cancer Cell 25(6): 735-747, 2014.

18 Wilop S, von Hobe S, Crysandt M, Esser A, Osieka R and Jost E: Impact of angiotensin i converting enzyme inhibitors and angiotensin II type 1 receptor blockers on survival in patients with advanced non-small-cell lung cancer undergoing first-line platinum-based chemotherapy. J Cancer Res Clin Oncol 135(10): 1429-1435, 2009
19 Tatokoro M, Fujii Y, Kawakami S, Saito K, Koga F, Matsuoka $\mathrm{Y}$, Iimura $\mathrm{Y}$, Masuda $\mathrm{H}$ and Kihara $\mathrm{K}$ : Phase-II trial of combination treatment of interferon-alpha, cimetidine, cyclooxygenase-2 inhibitor and renin-angiotensin-system inhibitor (I-CCA therapy) for advanced renal cell carcinoma. Cancer Sci 102(1): 137-143, 2011.

20 Keizman D, Huang P, Eisenberger MA, Pili R, Kim JJ, Antonarakis ES, Hammers H and Carducci MA: Angiotensin system inhibitors and outcome of sunitinib treatment in patients with metastatic renal cell carcinoma: A retrospective examination. Eur J Cancer 47(13): 1955-1961, 2011.

21 Cardinale D, Colombo A, Sandri MT, Lamantia G, Colombo N, Civelli M, Martinelli G, Veglia F, Fiorentini C and Cipolla CM: Prevention of high-dose chemotherapy-induced cardiotoxicity in high-risk patients by angiotensin-converting enzyme inhibition. Circulation 114(23): 2474-2481, 2006.

22 Nakagawa T, Kubota T, Kabuto $\mathrm{M}$ and Kodera T: Captopril inhibits glioma cell invasion in vitro: Involvement of matrix metalloproteinases. Anticancer Res 15(5B): 1985-1989, 1995.
Received October 4, 2017

Revised October 25, 2017

Accepted October 31, 2017 